Int. J. Dev. Biol. 60: 193-200 (2016)

doi: $10.1387 / \mathrm{ijdb} .160348 \mathrm{jk}$

\title{
MPF, starfish oocyte and cell-free extract in the background - an interview with Takeo Kishimoto
}

\author{
JACEK Z. KUBIAK*,1,2 and TAKEO KISHIMOTO*,3 \\ ${ }^{1}$ CNRS, UMR 6290, Institute of Genetics and Development of Rennes, Cell Cycle Group, Rennes, France, ${ }^{2}$ University Rennes \\ 1, UEB, IFR 140, Faculty of Medicine, Rennes, France and ${ }^{3}$ Ochanomizu University, Science \& Education Center, Bunkyo-ku, \\ Tokyo, Japan
}

\begin{abstract}
Professor Takeo Kishimoto's research has an enormous impact on the cell cycle field. Although his favorite model has always been a starfish oocyte, he has used many other model organisms in his research. Cell-free extracts have been wildly used in his laboratory as a very useful tool to answer cell cycle research questions. Recently, professor Kishimoto discovered the identity of the M-phase promoting factor (MPF) that was thought for years to be cyclin-dependent kinase 1 (CDK1). However, Takeo Kishimoto found that MPF consists in fact of two kinases: CDK1 and Greatwall kinase. While CDK1 phosphorylates mitotic substrates, Greatwall kinase allows these substrates to persist in their phosphorylated state because it regulates phosphatase PP2A, which dephosphorylates the majority of CDK1 substrates. When I started to interview Prof. Kishimoto, I was mostly interested in his experiences with cell-free extracts. However, as you will see below we almost immediately turned to the problem of the identity of MPF. This is fully understandable because the identity of MPF seems to be a major interest in Takeo's scientific career. I hope readers will enjoy this interview and will be able to learn about many aspects of scientific research, which do not usually appear in regular research papers.
\end{abstract}

KEY WORDS: CDK1, Cdc2, p34, Greatwall kinase, PP2A, cell cycle, cyclin B, oocyte maturation, MPF

During your scientific career you have worked on many different model organisms: the mouse, starfish, Xenopus... When and why did you decide to use cell-free extracts in your research?

Yes, I have worked on various organisms including the mouse, frog Bufo and Xenopus, starfish and sea cumber, mollusks, yeasts, and mammalian cultured cells. Looking back at my research career, however, the most important place in my research is taken by the starfish oocyte system. I think the other organisms complemented the starfish. I can now conclude that the starfish oocyte is one of the most effective and elegant model systems for the cell cycle study, although frankly, I have never been in love with the live starfish itself.

As for the use of cell-free extracts of Xenopus eggs, I think it originated from a paper by Manfred Lohka and Yoshio Masui (1983). This accomplishment was refined and established as the well-known cycling extract around 1990 by Andrew Murray and Marc Kirschner (Murray 1991). When the paper of Lohka and Masui was published, I had already worked on the frog oocytes (see below), but I did not plan to introduce the frog cell-free extracts. Instead, I tried, unsuccessfully, to develop the cell-free extracts from starfish eggs.

Several years later looking at enormous power of extracts in cell cycle studies, around 1990, I decided to introduce the frog egg cell-free extracts system. In 1991, I invited Dr. Keita Ohsumi, who had just obtained his PhD in Chiaki Katagiri lab of Hokkaido University, as a staff member to my lab in Tokyo Institute of Technology.

Ohsumi was perfect in both handling of Xenopus oocytes and eggs, and preparing the cell cycle extracts. He has a record of six rounds of full cell cycles observed in the extracts. Utilizing the cell-free extracts, he published many important papers starting with the one on the chromosome condensation without histone $\mathrm{H} 1$ (Ohsumi et al., 1993). He developed the meiotic cell cycle extracts (Iwabuchi et al., 2000), and clarified the molecular mechanism of

Abbreviations used in this paper: 1-MeAde, 1-methyladenine; CDK1, cyclin-dependent kinase 1; GV, germinal vesicle; Gwl, greatwall kinase; MPF, maturation/M-phase promoting factor; $\mathrm{PKB}$, protein kinase $\mathrm{B}$.

\footnotetext{
*Address correspondence to: Jacek Z. Kubiak. CNRS, UMR 6290, Institute of Genetics and Development of Rennes, Cell Cycle Group, Rennes, France. E-mail: jacek.kubiak@univ-rennes1.fr or toTakeo Kischimoto, Ochanomizu University, Science \& Education Center, Bunkyo-ku, Tokyo, Japan, E-mail: kishimoto.takeo@ocha.ac.jp
}

Accepted: 28 September, 2016. 
the CSF arrest (Nishiyama et al., 2007). Several PhD students who worked with Ohsumi are still using the Xenopus egg cell-free extracts in their current research.

\section{How did you start your scientific work? Have you always been interested in cell cycle regulation?}

At the beginning, the cell cycle was far away from my research scope. My scientific work started in the field of reproductive endocrinology of oocyte maturation in invertebrates. In July 1971, I joined as a first-year graduate student the lab of Haruo Kanatani, at Ocean Research Institute, University of Tokyo, who was working on starfish oocyte maturation. Two years prior, he determined the 1-methyladenine (1-MeAde) as the physiological inducer of starfish oocyte maturation, which is produced in the ovary under the influence of neural gonad-stimulating hormone (equivalent of GTH in vertebrates) and acts directly on the oocyte (Kanatani et al., 1969). This was the first identification of the maturation-inducing hormone in the animal kingdom, and thus it opened a window to utilize the starfish oocyte as a model system to analyze the mechanism of oocyte maturation. Owing to this finding, he was awarded the Pope Pio XI Gold Medal (Medaglia d'oro Pio XI) from the Vatican in 1970, and later, nominated as a foreign member of the French Academy of Science in 1981.

In 1970, a year before my participation, Kanatani had demonstrated in collaboration with Yukio Hiramoto that 1-MeAde acts on the oocyte surface (Kanatani and Hiramoto 1970). Based on this, my first research subject in Kanatani lab was to identify putative 1-MeAde-binding protein, which should be now called 1-MeAde receptor. It was nearly 10 years later that I became interested in cell cycle regulation at emergence of an idea that MPF (maturation/Mphase promoting factor) may be the general inducer of M-phase in eukaryotic cells. By the way, even now, molecular identity of the so-called 1-MeAde receptor remains unclear. Currently, it is my most important research subject to settle my first theme at the end of my research career.

Your research had an enormous impact on the field of the cell cycle and embryo development. Which of your works/papers do you think are the most important or the ones you are most proud of?

Thanks a lot. Until recently, my primary concern was to settle the question raised 35 years ago in my very old "Brief Notes" published in Dev. Biol., 1981, entitled "Role of germinal vesicle material in producing maturation-promoting factor in starfish oocyte" (Kishimoto et al., 1981). After its publication, there had been a long and tough struggle over 30 years in myself, but I feel now very happy that the question is eventually resolved in our recent papers (Hara et al., 2012 and Okumura et al., 2014) owing to surprising progress in the cell cycle research. Although the scientific story is reviewed in my recent article published in Chromosoma (Kishimoto 2015), I would like to mention here about its personal history.

Of course, it will be very interesting. Tell us how it started?

During my 5-year graduate course study in Kanatani lab, the first project on 1-MeAde binding protein had finished unsuccessfully, and then I moved to the MPF study in starfish oocytes at the beginning of 1974. In those days, MPF had been demonstrated only in oocytes and eggs of the frog Rana pipiens by Yoshio Masui and Clement Markert (1971). When this paper was published, the
Kanatani group had already had an idea of "MPF" in the starfish oocyte because a year before, they had published the 1-MeAde action on the oocyte surface (see above), but actually no one worked on this subject.

In the fiscal year 1973, Kanatani obtained research grants for the microinjection set such as Leitz micromanipulator, Narishige needle puller, etc. I then visited Prof. Yukio Hiramoto in Tokyo Institute of Technology in January of 1974 to learn microinjection technique and to start the starfish MPF project in Kanatani lab, because he was a world famous "superman" in this technique. Nearly14 years later I was offered the professorship at the Tokyo Institute of Technology after retirement of Hiramoto, although I had never dreamed of it at that time.

\section{Did you succeed in demonstrating starfish MPF?}

I set up the microinjection system in Kanatani lab, and soon succeeded in demonstrating starfish MPF through cytoplasmic transfer from an 1-MeAde-treated starfish oocyte to an untreated immature starfish oocyte. I think this was something like so-called beginner's luck.

I then tried to confirm Masui's observation in frog oocytes, in which MPF is detectable from enucleated as well as nucleated donor oocytes. Even after many trials, however, I found that this is not the case in the starfish oocyte. This was unexpected observation for us, and we were not able to find any convincing explanation, because we thought that MPF is a cytoplasmic mediator, which transduces the 1-MeAde signal from the oocyte surface to the germinal vesicle (GV)/nucleus, and hence that appearance of MPF should not depend on the presence of the GV. Accordingly, the GV issue was not included in our first starfish MPF paper, which was published in Nature (Kishimoto and Kanatani 1976) as a part of my $\mathrm{PhD}$ thesis.

\section{How did you come up to the publication of the GV issue?}

I had, nonetheless, been still concerned about the inconsistency between frog and starfish, and further confirmed requirement of the GV contents by restoration experiment, i.e., add back of the GV contents into 1-MeAde-treated enucleated oocytes, in collaboration with Setsuro Hirai from the Asamushi Marine Biological Station, Tohoku University. Finally, the GV requirement for MPF was published in Dev. Biol. (Kishimoto et al., 1981) (mentioned above), nearly 7 years after the initial finding. Our observation was soon confirmed by André Picard and Marcel Dorée (1984). Even so, however, we had to wait three decades to find a solution for why the GV content is required for MPF (Fig. 1).

\section{Can you tell me the scientific situation of MPF in those days around $1980 ?$}

In the late half of 1970s, MPF was demonstrated only in oocytes of frog and starfish. As seen in the naming by Masui, MPF was originally thought to be a cytoplasmic factor that can induce oocyte maturation (in a wording of the cell cycle, the meiotic G2/M-phase transition). Although the molecular identity of MPF remained unclear (just thought as a protein), the study of the role of MPF was entering into a new stage around the end of 1970s. Namely, starting with papers by Wasserman and Smith (1978) and by Rao's group (Sunkara et al., 1979) an idea was emerging that MPF might be a general inducer of $\mathrm{M}$-phase common to eukaryotic cells regardless of its origin in oocyte for meiosis or in somatic cell for mitosis. 
I know your significant contribution to establishing the generality of MPF by usage of many different organisms. Could you tell me how it started?

In those days, one of our interests was the species specificity of MPF. Because maturation-inducing hormones, progesterone for frog and 1-MeAde for starfish, are not cross-reactive between these animals, it was assumed that MPF might not be cross-reactive as well, even though its presence was demonstrated through similar cytoplasmic transfer. In the spring of 1978, nonetheless, we found that frog MPF can induce starfish oocyte maturation, although its publication took place much later (Kishimoto et al., 1982). Maybe, I should mention a funny story about this finding.

In May 1977, the National Institute for Basic Biology (NIBB) was founded in Okazaki, a suburb of Nagoya, as a national center of biology. Prof. Kanatani was much involved in funding and establishing NIBB, and I also moved to Okazaki in July 1977 as a staff in his lab. In Okazaki of those days, there were several ponds, not so far from NIBB, to which frogs Bufo bufo gather just after awake from hibernation. One evening in March 1978, we collected several wild Bufo and Kanatani injected pituitary homogenate to induce ovulation. The purpose was to prepare egg jelly from unfertilized mature eggs and the hormone injection was very much successful. As a result, many eggs were left unused. Looking at these eggs, I fell on an idea of getting frog MPF from them. Then I prepared Bufo egg extracts according to Wasserman and Masui method (1976), and injected them into immature starfish oocytes. Fortunately, Bufo eggs had not been activated and MPF was detectable. This was the beginning of our story on the MPF generality and also the start of my "association" with the frog oocyte system.

I think from the beginning of the MPF study, the most intriguing issue might have been to clarify the molecular identity of MPF. How and when was this done?

Certainly, Wasserman and Masui (1976) first succeeded in extracting MPF from frog oocytes. In my case, at first I planned to get $\mathrm{PhD}$ by molecular identification of the starfish MPF. Furthermore, an idea that MPF might be the general inducer of M-phase in eukaryotic cells prompted significant number of researchers to purify MPF (for example, Wu and Gerhart 1980). This trend changed the research field of MPF from reproductive endocrinology (at least in my case) to general cell biology, particularly, cell cycle control in M-phase. Accordingly, maturation promoting factor (MPF) was renamed M-phase promoting factor with the same abbreviation. Nonetheless, a wall against purification of MPF had been unusually high and tough, and many attempts, including mine, had finished in failure over a decade.

Finally, Manfred Lohka and Jim Maller succeeded in purifying Xenopus egg MPF by combination of conventional column chromatography with cell-free extracts assay (Lohka et al., 1988). This accomplishment converged immediately with Cdc2 of Paul Nurse and cyclin of Tim Hunt and Joan Ruderman, and it was established at the end of 1980s that MPF is a Ser/Thr kinase consisted of the cyclin B-Cdc2 complex (for reviews, Hunt,1989; Nurse 1990).

\section{What about your case and efforts in this direction?}

Indeed, the convergence of MPF, Cdc2 and cyclin B was a historical event in life science of the 20th century. Nevertheless, I failed to make any contribution to this big convergence. Regrettably and sadly, I was completely out of the drama, despite that I had continuously directed most of my energies to purifying starfish MPF.

Furthermore, the middle of 1980 s was unusually hard years for me. In December 1983, my important colleague Hirai in the GV-MPF issue suddenly passed away with heart attack at the age of 40 , and in February of the next year 1984, the lab head Kanatani passed away due to pancreatic cancer at the age of 54 . I needed to find a job outside NIBB. Although "fortunately" I got a job of professorship after Hiramoto in Tokyo Institute of Technology in December 1987, my major research proposal for this promotion was molecular identification of MPF. Surprisingly and "unfortunately", however, Maller's PNAS paper was published only a couple of months after my arrival at the new post; the p34 component of MPF turned out to be Cdc2 further a couple of month later (Dunphy et al., 1988; Gautier et al., 1988); and finally, the other component of MPF was settled down to cyclin B in the next year (Draetta et al., 1989; Labbe et al., 1989). Saying in a single word, my feeling at the start of my own lab was just like a sandbag of boxing.

\section{Too bad! You say you were once knocked down. How} then did you live through this terrible time?

There were two colleagues who invaluably saved my scientific life. The first, Kazunori Tachibana, who joined my group as a PhD student of Nagoya University and later as a staff scientist, had already succeeded in isolating a cDNA of starfish cyclin B at the beginning of 1988 (i.e., before the convergence of MPF, Cdc2 and cyclin). In fact, this was the first cDNA cloned in our lab (Tachibana et al., 1990). The second, Shinichi Hisanaga, who joined my group as an associate professor of Tokyo Institute of Technology in 1990, succeeded in obtaining very best antibody against starfish cyclin
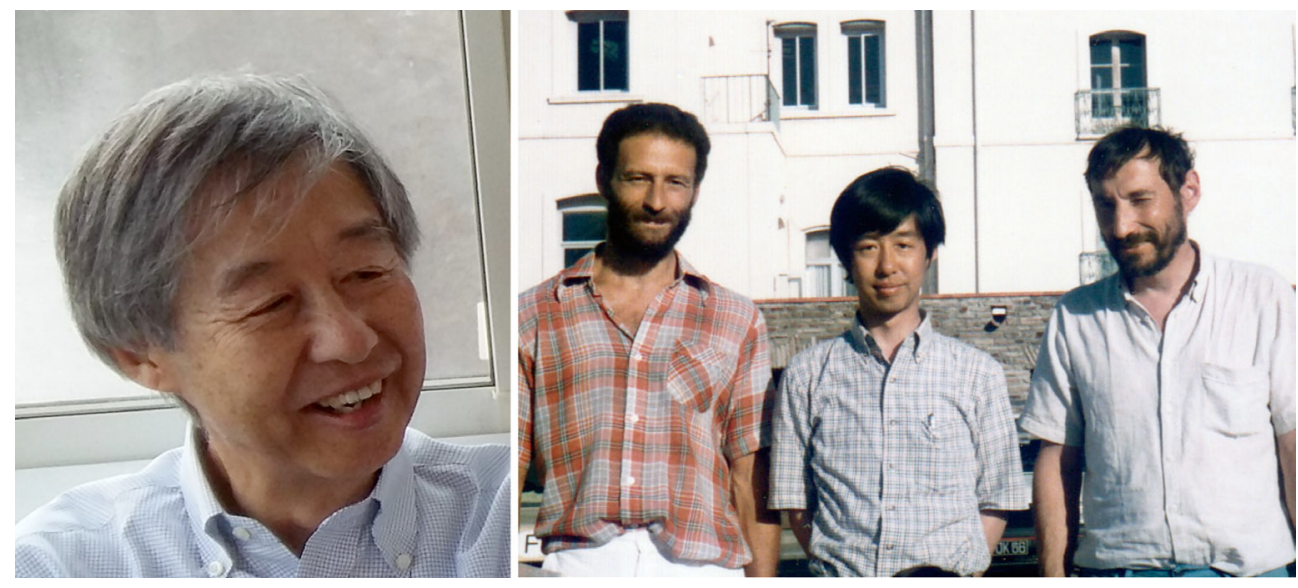

Fig. 1. Young starfish trio at Banyuls in 1985 and three decades later. From the right: Marcel Dorée, Takeo Kishimoto, André Picard, and again Takeo Kishimoto today. 
B. This was the first antibody, which we raised in rabbits by our own hands.

We then examined the dynamics of localization and kinase activity of the cyclin B-Cdc2 complex at the meiotic G2/M-phase transition in starfish oocytes. We found that the cyclin B-Cdc2 complex is exclusively cytoplasmic, that it is activated after 1-MeAde addition, and that then it accumulates in the GV/nucles, followed by GVBD/ nuclear envelope breakdown (Ookata et al., 1992). Although it was not included in this paper, we noticed at the same time that the cyclin B-Cdc2 complex is activated normally even in enucleated oocytes! That is, 1-MeAde-treated enucleated oocytes contain fully active cyclin B-Cdc2, whereas they do not have MPF! To our great delight, this observation implied that MPF is not identical to cyclin $\mathrm{B}-\mathrm{Cdc2}$. Certainly, the question what is MPF remained unsolved!!!

\section{Did you reach the answer about what MPF is soon?}

No, I did not. Even after this, it took two decades to reach a solution. In fact, it was not easy to continue to quest for the missing component of MPF under circumstance in which most researchers believed that MPF and cyclin B-Cdc2/Cdk1 were synonymous.

Yes, I can easily figure it out. Even after the convergence of MPF, Cdc2, and cyclin B, the big bang in cell cycle research continued and entered into the next stage. During the 1990s, various cyclins and various Cdc2related Cdks were discovered; then, the framework of the spindle assembly checkpoint and the DNA integrity checkpoint was elucidated, and finally a principle of cell cycle control was established based on both multiple cyclin-Cdk complexes and the checkpoint control (Nigg 2001). So, how did you control the research direction of your lab?

Our lab focused the research direction on the meiotic cell cycle control in oocytes of starfish and frog. The frog part was mainly performed by Ohsumi group, as mentioned at the beginning. In the starfish part, Tachibana group worked on the G1 arrest after completion of meiosis and its release by fertilization, and Eiichi Okumura group worked on the 1-MeAde signalling that leads to activation of cyclin B-Cdk1 at meiotic resumption. Accordingly, the missing GV/nuclear factor for MPF had been a continuous interest of Okumura group.

In the middle of 1990s, it was clarified that cyclin B-Cdk1 reaches its full activity via the autoregulatory activation loop, in which active cyclin B-Cdk1 activates its activator Cdc25 on one hand and inactivates its inactivator Wee1/Myt1 (Lew and Kornbluth 1996). However, it remained puzzling in any system what triggers the first activation of cyclin B-Cdk1 to start its auto-activation. In connection with this, we demonstrated the presence of this trigger downstream of 1-MeAde signaling in starfish oocytes (Okumura et al., 1996) and identified it as Akt/PKB (Okumura et al., 2002). That is, Akt/PKB directly phosphorylates and inactivates Myt1/activates Cdc25 to initiate the activation of cyclin B-Cdk1 (Fig. 2). As far as I know, even now, Akt/PKB is the only molecule that is clarified as an endogenous initiator of the cyclin B-Cdk1 autoregulatory activation loop.

\section{How did you find a way to the identification of the missing GV/nuclear factor?}

Akt/PKB is present in an inactive form and is activated in the cytoplasm. This excludes a possibility that Akt/PKB functions as the GV/nuclear factor of MPF. Our finding that Akt/PKB functions as an initial activator for cyclin B-Cdk1 supports an idea that the $\mathrm{GV} /$ nuclear factor might be required for the auto-regulatory activation of cyclin B-Cdk1.

In this connection, various mitotic kinases emerged from the big bang of the cell cycle research. Particularly, Plk1 and Aurora A looked very promising for us as well. In fact, Plk1 is proposed to be involved in the auto-activation loop for cyclin B-Cdk1. Nevertheless, finally we excluded both Plk1 and Aurora from a candidate for the GV/nuclear factor of MPF, because both are cytoplasmic and cyclin B-Cdk1 is activated almost normally in their absence (for Plk1, Okano-Uchida et al., 2003; for Aurora, Abe et al., 2010).

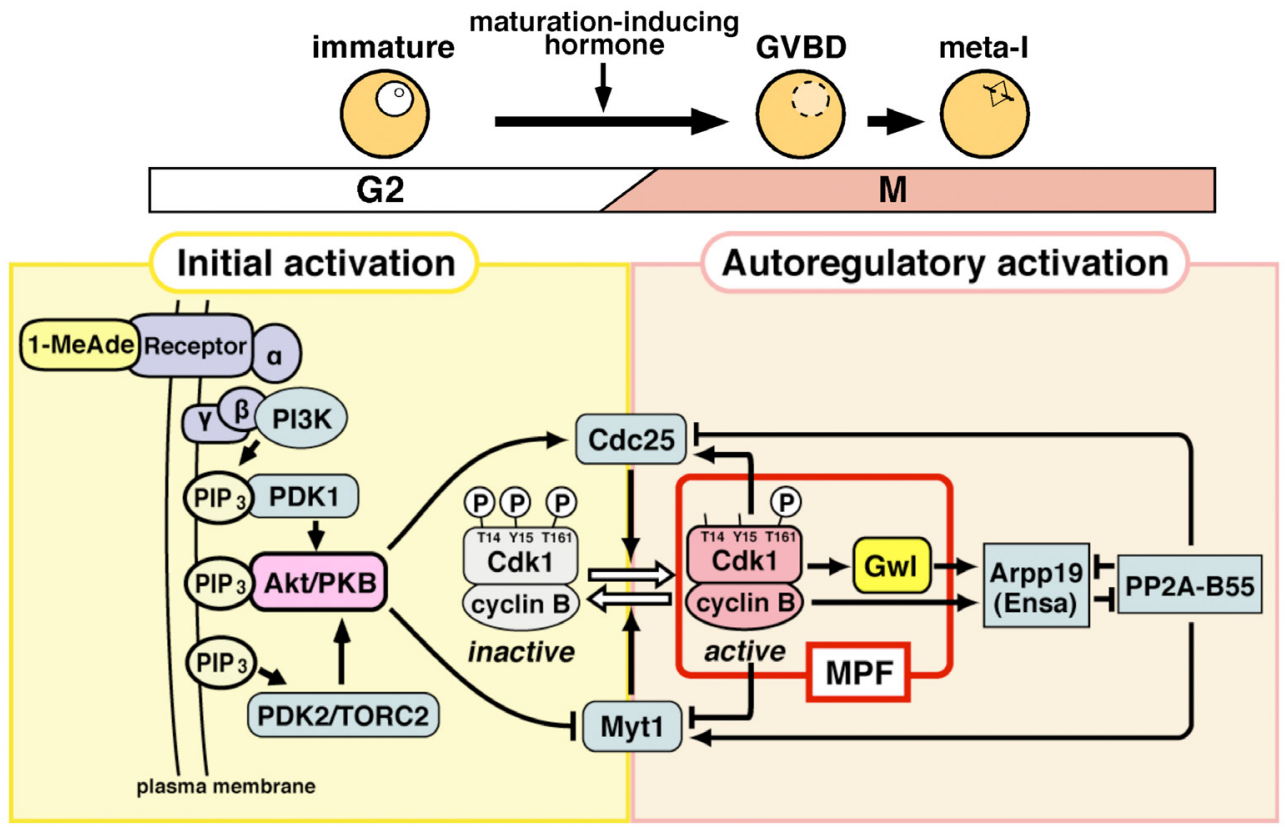

Fig. 2. Signaling pathway leading to Mphase promoting factor (MPF) activation in response to extracellular hormonal stimulus at meiotic G2/M-phase transition in starfish oocytes. Cyclin B-Cdk1 activation is accomplished via the initial activation step and the subsequent autoregulatoryactivation step. When maturationinducing hormone 1-MeAde induces the meiotic G2/M-phase transition in starfish oocytes, Akt/PKB functions as the initial activator of cyclin B-Cdk1 through direct phosphorylation of both Cdc25 and Myt1. In contrast, when MPF is introduced into recipient oocytes, MPF skips the Akt/PKBinduced initial activation step and is forced to start the cyclin B-Cdk1 autoactivation loop. This is the reason why, in addition to cyclin $B-C d k 1, G w l$ is further required for MPF. 
What was a turning point towards your breakthrough?

It was great findings by Mike Goldberg lab in Cornell University. In 2004, they identified a novel kinase, Greatwall (Gwl), in Drosophila. Surprisingly and most intriguingly, they found that Gwl is a nuclear, mitotic kinase required for normal progression of M-phase (Yu et al., 2004); and further that Gwl participates in the autoregulatory activation of cyclin B-Cdk1 (Yu et al., 2006). Their papers were introduced in our lab seminar by Masatoshi Hara, a PhD student in those days. Because their observations strongly suggested that Gwl must be our GV/nuclear factor required for MPF, we immediately started to work on starfish Gwl, first by isolating cDNA of starfish homolog of Gwl and next by raising antibodies against starfish Gwl.

\section{And how then did you reach the solution to the GV/ nuclear factor?}

We took steady aim at Gwl, and very exceptionally, almost every experiment progressed as we expected. Indeed, starfish Gwl was exclusively present in the GV/nucleus in immature/G2-phase oocytes, and began to be activated immediately after cyclin B-Cdk1. Most excitingly, Hara successfully raised a neutralizing antibody that can inhibit the kinase activity of Gwl, developed a method to get the antibody, which was microinjected in the cytoplasm, to accumulate into the GV/nucleus; and thus, produced a situation in which Gwl activity can be inhibited within starfish oocytes. As we expected, under suppression of Gwl activity, cyclin B-Cdk1 was activated almost normally, but MPF was undetectable after cytoplasmic transfer from these oocytes into normal immature oocytes. Conversely, enucleated oocytes, from which endogenous Gwl had been removed, restored MPF after they received recombinant Gwl. These observations clearly support an idea that MPF is not identical to cyclin B-Cdk1 and further that cyclin B-Cdk1 and Gwl are both critical constituents of MPF (Hara et al., 2012; Fig. 2).

\section{Congratulations!}

Thanks a lot. Certainly, to my greatest delight, we have at last resolved the three decades-long enigma that was born in our Dev. Biol. paper of 1981 (for review, Kishimoto 2015). As I mentioned earlier, the question had emerged at the age of me being a $\mathrm{PhD}$ student, and a solution was attained a year before my official retirement from Tokyo Institute of Technology. I think I should feel satisfied, because my own research team was able to find an answer. Needless to say, we were surely unable to reach the solution, unless huge progress in the cell cycle field, particularly including two separate kinases cyclin B-Cdk1 and Gwl, had been accomplished by so many researchers during these decades.

Your conclusion that cyclin B-Cdk1 and Gwl together constitute MPF looks very convincing. Nonetheless, I have several fundamental questions and much interest in your answers. So, I would like to discuss them with you. First, I think your story is based on the fact that Gwl is involved in the autoregulatory activation of cyclin B-Cdk1. If so, it is still difficult to understand why cyclin B-Cdk1 can be fully activated even in Gwl-free, enucleated starfish oocytes.

I agree that your question is very reasonable, and we now have a solution to this issue. But prior to explaining it, I should mention a conceptual change in the cell cycle research about the balance of opposing action between protein kinases and protein phosphatases.
Previously, M-phase was thought to be induced simply by increasing activity of kinases so that they overcome phosphatase activity, which remains constant throughout M-phase. But during the first decade of the 2000s, it became clear that the story is not so simple. To ensure swift and robust phase transitions, the phosphatase activity is generally suppressed at the entry into M-phase and recovered at the exit from M-phase, showing mirror image between kinase and phosphatase activities (Lindqvist et al., 2009; Qian et al., 2013). In this case, a major question should be how the phosphatase activity is turned off at the entry into M-phase. To resolve it, Gwl made a typical clear-cut contribution. In 2010, two groups, Anna Castro \& Thierry Lorca and Satoru Mochida \& Tim Hunt, found that Gwl directly phosphorylates Arpp19/Ensa, leading to the inhibition of PP2A-B55, a major phosphatase which antagonizes cyclin B-Cdk1, and that this pathway plays an essential role in the autoregulatory activation of cyclin B-Cdk1 (Gharbi-Ayachi et al., 2010; Mochida et al., 2010; Fig. 2).

We then investigated the reason why the autoregulatory activation of cyclin B-Cdk1 can occur even in the absence of Gwl/GV/ nucleus, and found the presence of a bypass in starfish oocytes. That is, independently of Gwl, cyclin B-Cdk1 itself (i.e., cyclin BCdk1 that is initially activated by Akt/PKB in the absence of Gwl) directly phosphorylates Arpp19 on the different site, which in turn is sufficient for inhibition of PP2A-B55 at least towards the autoregulatory activation of cyclin B-Cdk1 (Okumura et al., 2014; Fig. 2). I think this observation rationalizes your question.

Next, in frog oocytes, MPF is detectable even from enucleated oocytes as reported first by Masui and Markert (1971). How do you reconcile the discrepancy between frog and starfish oocytes?

This has long been intriguing for us as well, but we now know a solution. At least in Xenopus oocytes, Gwl is present in both the cytoplasm and the GV/nucleus. This exceptional localization is most likely to make MPF detectable even from enucleated frog oocytes (Hara et al., 2012).

Third, I am still most curious to know how you compromise with the well-known fact that microinjection of cyclin B-Cdk1 alone can induce the G2/M-phase transition in both frog and starfish oocytes.

Certainly, your concern is most essential. I would like to say again that we have already reached a solution. What we did was to compare the levels of cyclin B-Cdk1 activity required for the G2/Mphase transition following microinjection into oocytes, between purified cyclin B-Cdk1 alone and cyclin B-Cdk1 plus Gwl. In both starfish and frog oocytes, cyclin B-Cdk1 alone required one order of magnitude higher levels of activity than cyclin B-Cdk1 plus Gwl did. In brief, the addition of Gwl greatly reduced the required levels of cyclin B-Cdk1 activity, and most intriguingly, the reduced levels of cyclin B-Cdk1 activity was nearly equivalent to those contained in originally defined, cytoplasmic MPF. I should note that when extraordinarily high activity level of cyclin B-Cdk1 was introduced, the spindle formation was abortive even though nuclear envelope broke down (Hara et al., 2012).

Could you let me know what enabled you to accomplish such a semi-quantitative analysis of cyclin B-Cdk1 activity. As you may know, it is difficult for commer- 
cially available recombinant cyclin B-Cdk1 to induce the G2/M-phase transition in vivo due to its very low kinase activity.

Yes, that is an important issue in a real experiment. My old colleague Masaki Inagaki of the Aichi Cancer Center Research Institute developed a marvelously efficient method for one-step purification of endogenous cyclin B-Cdk1 at the beginning of the 1990s. In his procedure, although $\mathrm{p} 13^{\text {suc1 }}$-affinity column is used, cyclin B-Cdk1 is eluted by combination of $50 \%$ ethylene glycol and $0.5 \mathrm{M} \mathrm{NaCl}$ (detailed in Okumura et al., 1996). Owing to the Inagaki method, we believe that cyclin B-Cdk1 purified from starfish oocytes maintains even now a record of the highest activity along with the highest purity.

OK, coming back to your answer just before, could you explain why co-introduction of Gwl can reduce the required amounts of cyclin B-Cdk1.

Surely, it is a key point in this problem. I would like to remind you that the process for full activation of cyclin B-Cdk1 is consisted of two steps, the initial activation and the subsequent autoregulatory activation (Fig. 2). When the cell physiologically performs the G2/Mphase transition, the intracellular state is first inclined to cause the initial activation of cyclin B-Cdk1 (for example, the balance between Cdc25 and Myt1 is tipped by Akt/PKB in starfish oocytes). And small amount of the initially activated cyclin B-Cdk1 may start to phosphorylate Gwl and also PP1; the Gwl phosphorylation initiates its autophosphorylation, and the PP1 phosphorylation suppresses its counteraction against the Gwl autophosphorylation (Heim et al., 2015; Mochida 2015), leading to initiation of Gwl activation. Thus, prior to the start of the autoactivation loop, its upstream events have already accomplished and hence, the intracellular condition is "primed" for the autoregulatory activation of cyclin B-Cdk1.

In contrast, when the G2/M transition is induced by microinjection of cyclin B-Cdk1 alone, the whole "priming" process is skipped and hence, the injected cyclin B-Cdk1 is forced to start the autoactivation loop in the absence of "primed" condition. This rationalizes the requirement for extraordinarily high activity level of cyclin B-Cdk1. In such situation, it looks most reasonable that the co-introduced Gwl enhances autocatalysis of the loop and thus reduces the required amount of cyclin B-Cdk1.

\section{OK, I can follow each of your explanations. Nonetheless,}
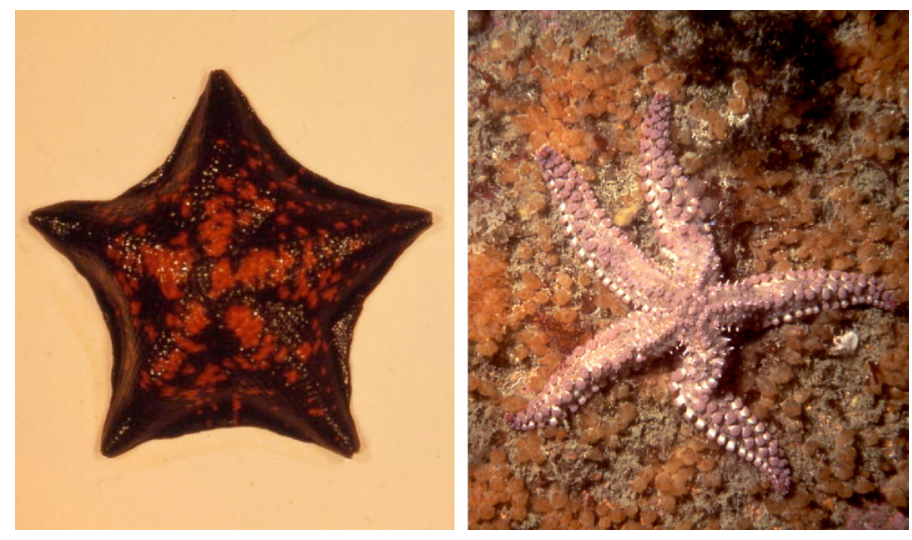

Fig. 3. Japanese and French starfish. Asterina pectinifera and Marthasterias glacialis. Photos: André Picard and Gérard Peaucellier. it is still difficult for me to reconcile with current belief that MPF is simply synonymous with cyclin B-Cdk1. Could you clear away the cobwebs out of my head?

Certainly, it is the most critical issue. I think there are two reasons for this confusion. One is the way for defining MPF, and the other is the above-mentioned process for full activation of cyclin B-Cdk1.

Currently, MPF (may be called "current MPF") is simply thought as an activity that can induce M-phase within the cell. Here, the idea of donor and recipient cells is out of assumption, and so to say, only the donor cell is assumed. In contrast, the original MPF (may be called "classical MPF") was functionally defined as an activity that can induce M-phase in recipient cells to which MPF is microinjected. In this cytoplasmic transfer, MPF is derived from donor cells but its presence is verified only by its activity in recipient cells. I think this different way for defining MPF causes the gap between the current MPF/cyclin B-Cdk1 alone and the classical MPF/cyclin B-Cdk1 + Gwl.

\section{How can this gap be explained by the process of full activation of cyclin B-Cdk1?}

One can assume a simple, one-way signaling cascade from upstream to downstream molecules. In this case, even if MPF was defined as a transferable activity, the classical MPF might be identical with the current MPF/cyclin B-Cdk1.

In a real, living cell, however, the signaling pathway is far more complex due to the feedback system in which the downstream molecule affects the upstream molecule. Indeed, at the G2/M-phase transition, as I mentioned above, the classical MPF is forced to skip the "primed" condition with the aid of Gwl and then accomplishes the full activation of cyclin B-Cdk1. In contrast, the current MPF accomplishes the same job under the "primed" condition. Thus, the gap between the current MPF and the classical MPF is derived from whether or not the "priming" towards the start of the cyclin B-Cdk1 autoregulatory activation loop are already satisfied.

\section{What are your thoughts after solving the decades-long enigma of MPF?}

First of all, it was too late because the enigma was left behind due to a major gap that was produced between the classical MPF and the current MPF during these decades. I think the essence of the enigma is composed of the autoregulatory activation loop and reversal of the balance between opposing kinases and phosphatases. Looking back at the literature, however, clues to elucidate these key issues were published much earlier. In the first MPF paper by Masui and Markert (1971), "amplification of MPF" was already demonstrated by serial cytoplasmic transfer experiment. In the current wording, amplification may be called the autoregulatory activation. Two decades later, but more than two decades before, André Picard and Marcel Dorée published a puzzling paper (Picard et al., 1991) in which okadaic acid, a potent inhibitor of PP2A and PP1, mimics the GV/nuclear factor of MPF. I should say that the present solution of the enigma is just a molecular explanation for these thought-provoking, early findings.

This interview started by talking about Xenopus egg extracts, but most of your talk was devoted to the starfish oocyte. I suppose you may have something to say about this?

Yes, you are right. Even after reading this interview, I suspect 
that some researchers may not be convinced by our conclusion that MPF consists of at least two separate kinases, cyclin B-Cdk1 and Gwl. Even so, I believe that they are convinced by usefulness of the starfish oocyte system. Of course, it is not my purpose to elucidate the specificity of the starfish oocyte. Instead, I am sure that the knowledge obtained in the starfish oocyte continuously has general impact to the study of metazoans throughout the past and the future (Fig. 3).

As the most recent examples, my current colleague Daisaku Hiraoka found that Akt/PKB needs unknown enhancing system to efficiently phosphorylate its substrates in intracellular environments (Hiraoka et al., 2016). This finding may ask reconsideration on Akt/PKB-related studies in a wide range of cells including mammals. Furthermore, I am very delighted that a series of works on meiotic chromosome behavior by Peter Lenart group (for example, Borrego-Pinto et al., 2016) are the most typical cases that gives a major impact from the starfish oocyte.

\section{So finally, how did the cell-free system add to this dis- covery? Was it important or secondary?}

To evaluate the involvement of Gwl in the frog oocyte MPF, we employed microinjection into immature Xenopus oocytes, but not the cell-free extracts. However, since the most of Gwl is localized in the cytoplasm in immature Xenopus oocytes, comparison between the starfish and the frog systems contributed very much to showing that reduction of the required amount of cyclin B-Cdk1 by $\mathrm{Gwl}$ is a general feature of $\mathrm{Gwl}$ regardless of its localization (Hara et al., 2012).

\section{This is the last question! Can you tell us what the future directions of your research are?}

I am now concentrating on two uncompleted subjects, 1-MeAde receptor with Okumura, and the starfish Asterina pectinifera genome with Prof. Takehiko Itoh of Tokyo Institute of Technology. These days, I feel so sad because the starfish oocyte community is now shrinking and shrinking whole over the world, despite of great potentiality of the starfish oocyte system. It is my hearty desire to complete these two projects within my research career, and to help survival of the starfish community.

\section{Thanks a lot for your thoughtful conversation. I enjoyed it very much.}

\section{References}

ABE Y, OKUMURA E, HOSOYA T, HIROTA T, KISHIMOTO T (2010). A single starfish Aurora kinase performs the combined functions of Aurora-A and Aurora-B in human cells. J Cell Sci 123: 3978-3988.

ORREGO-PINTO J, SOMOGYIK, KARREMAN MA, KONIG J, MULLER-REICHERT T, BETTENCOURT-DIAS M, GONCZY P, SCHWAB Y, LENART P (2016). Distinct mechanisms eliminate mother and daughter centrioles in meiosis of starfish oocytes. J Cell Biol 212: 815-827.

DRAETTA G, LUCA F, WESTENDORF J, BRIZUELA L, RUDERMAN J, BEACH D (1989). cdc2 Protein kinase is complexed with both cyclin A and B: Evidence for proteolytic inactivation of MPF. Cell 56: 829-838.

DUNPHY WG, BRIZUELA L, BEACH D, NEWPORT J (1988). The Xenopus cdc2 protein is a component of MPF, a cytoplamic regulator of mitosis. Cell54:423-431.

GAUTIER J, NORBURY C, LOHKA M, NURSE P, MALLER J (1988). Purified maturation-promoting factor contains the product of a Xenopus homolog of the fission yeast cell cycle control gene cdc2 $2^{+}$. Cell 54: 433-439.

GHARBI-AYACHI A, LABBE JC, BURGESS A, VIGNERON S, STRUB JM, BRI-
OUDES E, VAN-DORSSELAER A, CASTRO A, LORCA T (2010). The substrate of Greatwall kinase, Arpp19, controls mitosis by inhibiting protein phosphatase 2A. Science 330: 1673-1677.

HARA M, ABE Y, TANAKA T, YAMAMOTO T, OKUMURA E, KISHIMOTO T (2012). Greatwall kinase and cyclin B-Cdk1 are both critical constituents of M-phase promoting factor. Nat Commun 3: 1059, doi: 10.1038/ncomms2062.

HEIM A, KONIETZNY A, MAYER TU (2015). Protein phophatase 1 is essential for Greatwall inactivation at mitotic exit. EMBO Rep 16: 1501-1510.

HIRAOKA D, AONO R, HANADA S, OKUMURA E, KISHIMOTO T (2016). Two new competing pathways establish the threshold for cyclin B-Cdk1 activation at the meiotic G2/M transition. J Cell Sci 129: 3153-3166.

HUNT T (1989). Maturation promoting factor, cyclin and the control of M-phase. Curr Opin Cell Biol 1: 268-274.

IWABUCHI M, OHSUMI K, YAMAMOTO TM, SAWADA W, KISHIMOTO T (2000). Residual Cdc2 activity remaining at meiosis I exit is essential for meiotic M-M transition in Xenopus oocyte extracts. EMBO J 19: 4513-4523.

KANATANI H, HIRAMOTO Y (1970). Site of action of 1-methyladenine in inducing oocyte maturation in starfish. Exp Cell Res 61: 280-284.

KANATANI H, SHIRAI H, NAKANISHI K, KUROKAWA T (1969). Isolation and identification of meiosis inducing substance in starfish Asterias amurensis. Nature 221: $273-274$

KISHIMOTO T (2015). Entry into mitosis: a solution to the decades-long enigma of MPF. Chromosoma 124: 417-428.

KISHIMOTO T, KANATANI H (1976). Cytoplasmic factor responsible for germina vesicle breakdown and meiotic maturation in starfish oocyte. Nature 260:321-322.

KISHIMOTO T, HIRAI S, KANATAN H (1981). Role of germinal vesicle material in producing maturation-promoting factor in starfish oocyte. Dev Biol 81: 177-181.

KISHIMOTO T, KURIYAMA R, KONDO H, KANATANI H (1982). Generality of the action of various maturation-promoting factors. Exp Cell Res 137: 121-126.

LABBE JC, CAPONY JP, CAPUT D, CAVADORE JC, DERANCOURT J, KAGHAD M, LELIAS JM, PICRD A, DOREE M (1989). MPF from starfish oocytes at the first meiotic metaphase is a heterodimer containing one molecule of cdc2 and one molecule of cyclin B. EMBO J 8: 3053-3058.

LEW DJ, KORNBLUTH S (1996). Regulatory roles of cyclin dependent kinase phosphorylation in cell cycle control. Curr Opin Cell Biol 8: 795-804.

LINDQVIST A, RODRIGUEZ-BRAVO V, MEDEMA RH (2009). The decision to enter mitosis: feedback and redundancy in the mitotic entry network. J Cell Biol 185: 193-202.

LOHKA MJ, HAYES MK, MALLER JL (1988). Purification of maturation-promoting factor, an intracellular regulator of early mitotic events. Proc Natl Acad Sci USA 85: 3009-3013.

LOHKA M, MASUI Y (1983). Formation in vitro of sperm pronuclei and mitotic chromosomes induced by amphibian ooplasmic components. Science 220: 719-721.

MASUI Y, MARKERT CL (1971). Cytoplasmic control of nuclear behavior during meiotic maturation of frog oocytes. J Exp Zool 177: 129-145.

MOCHIDA S (2015). PP1 inactivtes Greatwall to release PP2A-B55 from mitotic confinement. EMBO Rep 16: 1411-1412.

MOCHIDA S, MASLEN SL, SKEHEL M, HUNT T (2010). Greatwall phosphorylates an inhibitor of protein phosphatase $2 \mathrm{~A}$ that is essential for mitosis. Science 330 : 1670-1673.

MURRAY AW (1991). Cell cycle extracts. Methods Cell Biol 36: 581-605.

NIGG EA (2001). Mitotic kinases as regulators of cell division and its checkpoints. Nat Rev Mol Cell Biol 2: 21-32.

NISHIYAMA T, OHSUMI K, KISHIMOTO T (2007). XErp1 phosphorylation by p90Rsk is required for cytostatic factor arrest in Xenopus eggs. Nature 446: 1096-1099.

NURSE P (1990). Universal control mechanism regulating onset of M-phase. Nature 344: 503-508.

OHSUMI K, KATAGIRI CH, KISHIMOTO T (1993). Chromosome condensation in Xenopus mitotic extracts without histone H1. Science 262: 2033-2035.

OKANO-UCHIDA T, OKUMURA E, IWASHITA M, YOSHIDA H, TACHIBANA K, KISHIMOTO T (2003). Distinct regulators for Plk1 activation in starfish meiotic and early embryonic cycles. EMBO J 22: 5633-5642.

OKUMURA E, FUKUHARA T, YOSHIDA H, HANADA S, KOZUTSUMI R, MORI M, TACHIBANA K, KISHIMOTO T (2002). Akt inhibits Myt1 in the signalling pathway 
that leads to meiotic G2/M-phase transition. Nat Cell Biol 4: 111-116.

OKUMURA E, MORITAA, WAKAI M, MOCHIDA S, HARA M, KISHIMOTO T (2014). Cyclin B-Cdk1 inhibits protein phosphatase PP2A-B55 via a Greatwall kinaseindependent mechanism. J Cell Biol 204: 881-889.

OKUMURA E, SEKIAI T, HISANAGAS, TACHIBANAK, KISHIMOTO T (1996). Initial triggering of $\mathrm{M}$-phase in starfish oocytes: a possible novel component of maturationpromoting factor besides cdc2 kinase. J Cell Biol 132: 125-135.

OOKATAK, HISANAGAS, OKANO T, TACHIBANAK, KISHIMOTO T (1992). Relocation and distinct subcellular localization of p34cdc2-cyclin B complex at meiosis reinitiation in starfish oocytes. EMBO J 11: 1763-1772.

PICARDA, DOREE M (1984). The role of the germinal vesicle in producing maturationpromoting factor (MPF) as revealed by the removal and transplantation of nuclear material in starfish oocytes. Dev Biol 104: 357-365.

PICARD A, LABBE JC, BARAKAT H, CAVADORE JC, DOREE M (1991). Okadaic acid mimics a nuclear component required for cyclin B-cdc2 kinase microinjection to drive starfish oocytes into M phase. J Cell Biol 115: 337-344.

QIAN J, WINKLER C, BOLLEN M (2013). 4D-networking by mitotic phosphatases. Curr Opin Cell Biol 25: 697-703.
SUNKARA PS, WRIGHT DA, RAO PN (1979). Mitotic factors from mammalian cells induce germinal vesicle breakdown and chromosome condensation in amphibian oocytes. Proc Natl Acad Sci USA 76: 2799-2802.

TACHIBANA K, ISHIURA M, UCHIDA T, KISHIMOTO T (1990). The starfish egg mRNA responsible for reinitiation of meiotic maturation encodes cyclin. Dev Biol 140: $241-252$

WASSERMAN WJ, MASUI Y (1976). A cytoplasmic factor promoting oocyte maturation: Its extraction and preliminary characterization. Science 191: 1266-1268.

WASSERMAN WJ, SMITH LD (1978). The cyclic behavior of a cytoplasmic factor controlling nuclear membrane breakdown. J Cell Biol 78: R15-R22.

WUM, GERHART JC (1980). Partial purification and characterization of the manturationpromoting factor from eggs of Xenopus laevis. Dev Biol 79: 465-477.

YU J, FLEMING SL, WILLIAMS B, WILLIAMS EV, LI Z, SOMMA P, RIEDER CL, GOLDBERG ML (2004). Greatwall kinase: a nuclear protein required for proper chromosome condensation and mitotic progression in Drosophila. J Cell Biol 164: 487-492

YU J, ZHAO Y, LI Z, GALAS S, GOLDBERG ML (2006). Greatwall kinase participates in the Cdc2 autoregulatory loop in Xenopus egg extracts. Mol Cell 22: 83-91. 


\section{Further Related Reading, published previously in the Int. J. Dev. Biol.}

Control of timing of embryonic M-phase entry and exit is differentially sensitive to CDK1 and PP2A balance Mohammed El Dika, Damian Dudka, Claude Prigent, Jean-Pierre Tassan, Malgorzata Kloc and Jacek Z. Kubiak Int. J. Dev. Biol. (2014) 58: 767-774

Identification of the sperm motility-initiating substance in the newt, Cynops pyrrhogaster, and its possible relationship with the acrosome reaction during internal fertilization

Toshihiko Watanabe, Hideo Kubo, Shinya Takeshima, Mami Nakagawa, Manami Ohta, Saori Kamimura, Eriko Takayama-Watanabe, Akihiko Watanabe, and Kazuo Onitake

Int. J. Dev. Biol. (2010) 54: 591-597

Signalling molecules involved in mouse bladder smooth muscle cellular differentiation

Benchun Liu, Dongxiao Feng, Guiting Lin, Mei Cao, Yuet Wai Kan, Gerald R. Cunha and Laurence S. Baskin

Int. J. Dev. Biol. (2010) 54: 175-180

Nuclear reprogramming in zygotes

Chanchao Lorthongpanich, Davor Solter and Chin Yan Lim

Int. J. Dev. Biol. (2010) 54: 1631-1640

Faithful reprogramming to pluripotency in mammals - what does nuclear transfer teach us? Julien Maruotti, Alice Jouneau and Jean-Paul Renard Int. J. Dev. Biol. (2010) 54: 1609-1621

Gonad-stimulating substance-like molecule from the radial nerve of the sea cucumber Hideki Katow, Tomoko Katow and Akihiko Moriyama Int. J. Dev. Biol. (2009) 53: 483-491

Cyclin B2/cyclin-dependent kinase1 dissociation precedes CDK1 Thr-161 dephosphorylation upon M-phase promoting factor inactivation in Xenopus laevis cell-free extract

Franck Chesnel, Franck Bazile, Aude Pascal and Jacek Z. Kubiak

Int. J. Dev. Biol. (2007) 51: 297-305

Remodeling of sperm chromatin induced in egg extracts of amphibians.

$\mathrm{C}$ Katagiri and K Ohsumi

Int. J. Dev. Biol. (1994) 38: 209-216

The influence of mouse sera, regenerating liver extracts and bacterial products on the abilities of different cells in vitro. N Zarkovic, M Osmak, D Novak, N Lers and M Jurin Int. J. Dev. Biol. (1991) 35: 239-249

Hormonal factors from the mammalian pineal gland interfere with cell development in Hydra. W A Müller, C Bartsch, H Bartsch, I Maidonis and E Bayer

Int. J. Dev. Biol. (1998) 42: 821-824
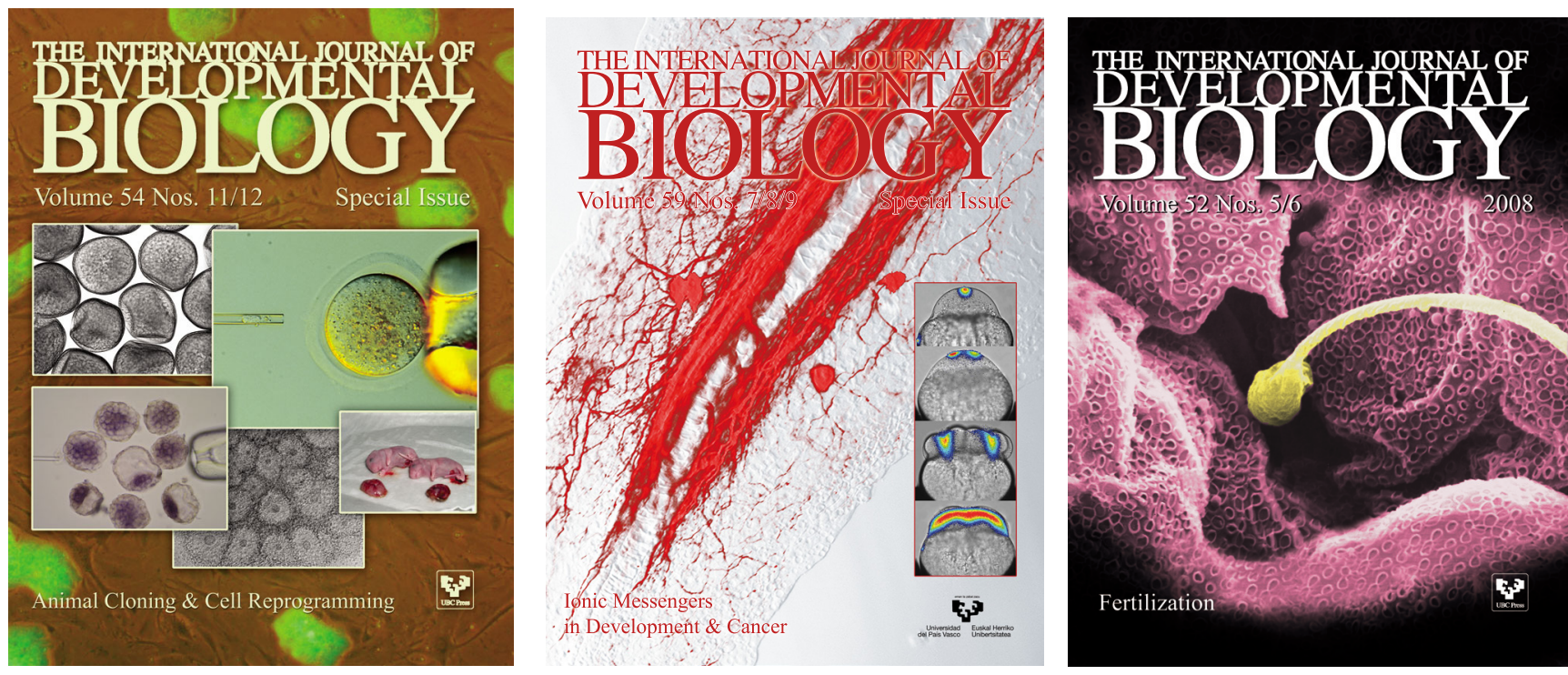